\title{
Synthesis, Applications and Toxicological Aspects of Silver Nanoparticles
}

\author{
Zorawar Singh ${ }^{1}$, JasjitKaur Randhawa ${ }^{1}$, Sarabtej Singh Wilkhu ${ }^{2 *}$, Swati Sharma $^{1}$ \\ ${ }^{I}$ Department of Zoology, Khalsa College Amritsar, Punjab, India. \\ ${ }^{2}$ Department of Chemistry, SMJMS, Hoshiarpur Road, Phagwara, Punjab, India.
}

*Corresponding Author: Sarabtej Singh Wilkhu, Department of Chemistry, SMJMS, Hoshiarpur Road, Phagwara, Punjab, India.

\begin{abstract}
Silver nanoparticles (SNPs) are particles of silver between 1- $100 \mathrm{~nm}$ in size. Over the past few decades, nanoparticles of noble metals such as silver have been found to exhibit significantly distinct physical, chemical, and biological properties from their bulk counterparts. Nano-sized particles of less than $100 \mathrm{~nm}$ in diameter are attracting the scientific community for the wide range of new applications in various fields of industry. Such nano-powders can exhibit properties that differ substantially from those of bulk materials, as a result of small particles dimension, high surface area and quantum confinements. Most of the unique properties of nanoparticles require not only the particles to be of nano-sized, but also the particle be dispersed without agglomeration. Toxicological aspects of silver nanoparticles are yet to be found particularly in humans. Thus, this paper discusses the synthesis, applications and toxicity of silver nanoparticles through available reports.
\end{abstract}

Keywords: Silver nanoparticles, synthesis, toxicity, applications, silver, environment, nanotoxicology

\section{INTRODUCTION}

Nanotechnology is a science that deals with engineering particles on a near atomic scale that at least one dimension in the range of 1-100 nanometres (nm). Relatively little is known about the behavior and toxicity of nanoparticles in the environment. Silver nanoparticles (SNPs) are nanoparticles of silver of between 1- $100 \mathrm{~nm}$ in size[1]. Nano-sized particles of less than $100 \mathrm{~nm}$ in diameter are attracting the scientific community for the wide range of new applications in various fields of industry[2-5]. Over the past few decades, nanoparticles of noble metals such as silver have been found to exhibit significantly distinct physical, chemical, and biological properties from their bulk counterparts. Such powders can exhibit properties that differ substantially from those of bulk materials, as a result of small particles dimension, high surface area and quantum confinements. Although SNPs are increasingly used in various consumer products and produced in industrial scale, information on harmful effects of nanosilver to environmentally relevant organisms is still scarce[6].During recycling or disposal, these engineered nanoparticles are likely to expose to the environment. Once released these engineered nanoparticles undergo transformations via biotic and abiotic processes and are likely to become yet another anthropogenic source. Toxicological aspects of silver nanoparticles are yet to be found particularly in humans. The toxicity of SNPs has been shown in many publications[6-10]. This paper reviews the synthesis, applications and toxicological aspects of SNPs from the available reports.

\section{SYNTHESIS}

Silver nanoparticles can be synthesized by several methods.

\subsection{Ion implantation}

Ion implantation has been used to create silver nanoparticles embedded in glass, polyurethane, silicon, polyethylene and polymethylmethacrylate. The particles grow in the substrate with the bombardment of ions. 


\subsection{Wet chemistry}

Wet methods for creating silver nanoparticles typically involve the reduction of a silver salt such as silver nitrate with a reducing agent like sodium borohydride in the presence of colloidal stabilizer. Sodium borohydride has been used with polyvinyl alcohol, poly(vinylpyrrolidone), bovine serum albumin, citrate and cellulose as stabilizing agents. A one-pot synthesis of crystalline silver nanoparticles was recently reported.

\subsection{Biogenic synthesis}

The biological synthesis of nanoparticles has provided a means for improved techniques and methods in the medicinal field. Biogenic methods can be used to make nanoparticles of different chemical compositions, sizes, and shapes without the use of toxic ingredients as used currently in synthetic protocols. In addition, precise control over shape and size is vital during nanoparticle synthesis since the nanoparticles therapeutic properties are intimately dependent on such factors. Hence, the primary focus of research in biogenic synthesis is in developing methods that consistently reproduce nanoparticles with precise properties.

\subsection{Plant derived synthesis}

Interestingly, an alternate method of synthesizing silver nanoparticles comes from the extracts of plant material, commonly referred to as "green synthesis. Extracts from flowers such as Geranium and many pepper species have been used as the initial reducing agent of $\mathrm{Ag}^{+}$in the first step of nanoparticle synthesis. The extract can be mixed with silver nitrite and treated with distilled water acetone and ethanol to crystalline the colloid suspension. The resultant silver nanoparticles are synthesized without the use of harmful reagents such as sodium borohydride and sodium citrate.

\subsection{Bacterial and fungal synthesis}

Bacterial and fungal synthesis of nanoparticles is practical because bacteria and fungi are easy to handle and can be modified genetically with ease. This provide a means to develop biomolecules that can synthesize silver nanoparticles of varying shapes and size in high yield, which is at the forefront of current challenges in nanoparticles synthesis. Fungus such as Verticilliumand bacterial stains such as Klebsiellapneumoniaecan be used in the synthesis of silver nanoparticles.

\section{ApPliCATIONS}

Silver nanoparticles are being used in numerous technologies and incorporated into a wide array of consumer products that take advantage of their desirable optical, conductive and antibacterial properties.

3.1 Diagnostic application: Silver nanoparticles are used in biosensors and numerous assays where the silver nanoparticle materials can be used as biological tags for quantitative detection.

3.2 Antibacterial applications: Silver nanoparticles are incorporated in apparel, footwear, paints, wound dressing, appliances, cosmetics and plastics for their antibacterial properties.

3.3 Conductive applications: Silver nanoparticles are used in conductive inks and integrated into composites to enhance thermal and electrical conductivity.

3.4 Optical application: Silvernanoparticlesare usedtoefficientlyharvest light and for enhanced optical spectroscopies.

3.5 Silver nanowires: Silver nanowires are an exciting class of silver nanoparticles which have been studied as possible component in many advance technology applications which include conductive coating (for transparent conductors and flexible electronics), plasmonic antennas (functions as antennas enhancing plasmonic activity for sensing and imaging application), molecular sensing and in nanocomposites.

\section{NANOTOXicological Studies}

Different available researches have shown the SNPs to be toxic [11;12]. Kawataet.al. [13] evaluated in vitro toxicity of SNP's at non cytotoxic doses to Hep G2 human hepatoma cells based on cell viability assay.Micronucleus test and DNA microarray analysis were done and it was concluded that both nano 
sized particles of $\mathrm{Ag}$ as well as ionic $\mathrm{Ag}^{+}$contribute to toxic effect of SNP's by causing cell proliferation at low dose $(<0.5 \mathrm{mg} / \mathrm{L})$, exhibited cytotoxicity at higher doses $(>1.0 \mathrm{mg} / \mathrm{L})$ and induced abnormal cellular morphology, displaying cellular shrinkage and acquisition of an irregular space. SNP's exposure increases the frequency of micronucleus formation and thus causes much stronger damage to chromosomes. Kim et.al. [14]studied the oxidative stress-dependent toxicity of silver nanoparticles in human hepatoma cells. The study concluded that cytotoxicity is primarily the result of oxidative stress and is independent of toxicity of $\mathrm{Ag}^{+}$ion.

Hackenberget.al. [15]studied SNP's in evaluation of DNA damage, toxicity and functional impairment in human mesenchymal stem cells (hMSC's) and they revealed that cytogenotoxic potential of SNPs in hMSC's at significantly higher concentrations as compared to antimicrobial effective levels.Bohmertet.al. [8]studied the analytically monitored digestion of SNP's and their toxicity in human intestinal cells and concluded that SNPs may overcome the gastrointestinal juices in their particulate form without forming large quantity of aggregates. These particles can reach the intestinal epithelial cells after ingestion with only a slight reduction in their cytotoxic potential. Study indicates that the NP impact body fluids to provide a reliable interpretation of their nano-specific cytotoxicity testing in vivo and in vitro.

\section{CONCLUSiON}

Silver nanoparticles (SNPs) have been synthesized by different methods. Their worldwide distribution in the ecosystem raises concern over the toxicity of these moieties to humans. Different authors have demonstrated the production of reactive oxygen species and cytotoxicity of SNPs in human cell lines. Thus, the exposure to SNPs should be checked and minimized.

\section{REFERENCES}

[1] Allen HJ, Impellitteri CA, Macke DA, Heckman JL, Poynton HC, Lazorchak JM, Govindaswamy S, Roose DL, Nadagouda MN: Effects from filtration, capping agents, and presence/absence of food on the toxicity of silver nanoparticles to Daphnia magna. Environ Toxicol Chem 2010;29:2742-2750.

[2] Singh Z: Applications and toxicity of graphene family nanomaterials and theircomposites. Nanotech Sci App 2016;9:15-28.

[3] Singh Z: Toxicity of Graphene and its Nanocomposites to Human Cell Lines- The Present Scenario . Int J Biomed Clin Sci 2016;1:24-29.

[4] Singh Z, Singh R: Toxicity of Graphene Based Nanomaterials Towards different Bacterial Strains: A Comprehensive Review. American J Life Sci 2017;5:1-9.

[5] Singh Z, Singh R: Recent Approaches in Use of Graphene Derivatives in Anticancer Drug Delivery Systems. J Drug Design Res 2017;4:1041-1044.

[6] Blinova I, Niskanen J, Kajankari P, Kanarbik L, Kakinen A, Tenhu H, Penttinen OP, Kahru A: Toxicity of two types of silver nanoparticles to aquatic crustaceans Daphnia magna and Thamnocephalus platyurus. Environ Sci Pollut Res Int 2013;20:3456-3463.

[7] Ashraf S, Abbasi AZ, Pfeiffer C, Hussain SZ, Khalid ZM, Gil PR, Parak WJ, Hussain I: Protein-mediated synthesis, pH-induced reversible agglomeration, toxicity and cellular interaction of silver nanoparticles. Colloids Surf B Biointerfaces 2013;102:511-518.

[8] Bohmert L, Girod M, Hansen U, Maul R, Knappe P, Niemann B, Weidner SM, Thunemann AF, Lampen A: Analytically Monitored Digestion of Silver Nanoparticles and their Toxicity for Human Intestinal Cells. Nanotoxicology 2013.

[9] Chairuangkitti P, Lawanprasert S, Roytrakul S, Aueviriyavit S, Phummiratch D, Kulthong K, Chanvorachote P, Maniratanachote R: Silver nanoparticles induce toxicity in A549 cells via ROSdependent and ROS-independent pathways. Toxicol In Vitro 2013;27:330-338.

[10] Cho JG, Kim KT, Ryu TK, Lee JW, Kim JE, Kim J, Lee BC, Jo EH, Yoon J, Eom IC, Choi K, Kim P: Stepwise Embryonic Toxicity of Silver Nanoparticles on Oryzias latipes. Biomed Res Int 2013;2013:494671.

[11] Navarro E, Piccapietra F, Wagner B, Marconi F, Kaegi R, Odzak N, Sigg L, Behra R: Toxicity of silver nanoparticles to Chlamydomonas reinhardtii. Environ Sci Technol 2008;42:8959-8964.

[12] Sung JH, Ji JH, Park JD, Yoon JU, Kim DS, Jeon KS, Song MY, Jeong J, Han BS, Han JH, Chung YH, Chang HK, Lee JH, Cho MH, Kelman BJ, Yu IJ: Subchronic inhalation toxicity of silver nanoparticles. Toxicol Sci 2009;108:452-461. 
[13] Kawata K, Osawa M, Okabe S: In vitro toxicity of silver nanoparticles at noncytotoxic doses to HepG2 human hepatoma cells. Environ Sci Technol 2009;43:6046-6051.

[14] Kim S, Choi JE, Choi J, Chung KH, Park K, Yi J, Ryu DY: Oxidative stress-dependent toxicity of silver nanoparticles in human hepatoma cells. Toxicol In Vitro 2009;23:1076-1084.

[15] Hackenberg S, Scherzed A, Kessler M, Hummel S, Technau A, Froelich K, Ginzkey C, Koehler C, Hagen R, Kleinsasser N: Silver nanoparticles: evaluation of DNA damage, toxicity and functional impairment in human mesenchymal stem cells. Toxicol Lett 2011;201:27-33.

Citation: Z. Singh et al., "Synthesis, Applications and Toxicological Aspects of Silver Nanoparticles", International Journal of Research Studies in Zoology, vol. 4, no. 2, p. 17-20, 2018. http://dx.doi.org/ 10.20431/2454-941X.0402004

Copyright: (C) 2018 Z. Singh et al. This is an open-access article distributed under the terms of the Creative Commons Attribution License, which permits unrestricted use, distribution, and reproduction in any medium, provided the original author and source are credited. 